\title{
THE
}

\section{Motivation to change alcohol use and treatment engagement in incarcerated youth}

\author{
Mary Clair \\ University of Rhode Island \\ L.A.R. Stein \\ University of Rhode Island, larstein@uri.edu \\ Rosemarie Martin \\ Nancy P. Barnett \\ Suzanne M. Colby
}

See next page for additional authors

Follow this and additional works at: https://digitalcommons.uri.edu/psy_facpubs

This is a pre-publication author manuscript of the final, published article.

Creative Commons License

\section{c) (i) $\ominus$}

This work is licensed under a Creative Commons Attribution-Noncommercial-No Derivative Works 4.0 License.

\section{Citation/Publisher Attribution}

Clair, Mary, et al. "Motivation to change alcohol use and treatment engagement in incarcerated youth." Addictive Behaviors, vol. 36, no. 6, 2011, pp. 674-680. doi: 10.1016/j.addbeh.2011.01.007 Available at: https://doi.org/10.1016/j.addbeh.2011.01.007 


\section{Authors}

Mary Clair, L.A.R. Stein, Rosemarie Martin, Nancy P. Barnett, Suzanne M. Colby, Peter M. Monti, Charles Golembeske Jr., and Rebecca Lebeau 


\title{
Motivation to Change Alcohol Use and Treatment Engagement in Incarcerated Youth
}

\author{
Mary Clair, Ph.D.b,c, L.A.R. Stein, Ph.D. ${ }^{a, b, c}$, Rosemarie Martin, Ph.D. ${ }^{a}$, Nancy P. Barnett, \\ Ph.D. ${ }^{a}$, Suzanne M. Colby, Ph.D. ${ }^{a}$, Peter M. Monti, Ph.D. ${ }^{\text {a,d }}$, Charles Golembeske Jr., \\ Ph.D. ${ }^{a, b, c}$, and Rebecca Lebeau, Ph.D. ${ }^{\mathrm{C}}$ \\ ${ }^{a}$ Center for Alcohol and Addictions Studies, Brown University, 121 South Main Street, \\ Providence, RI 02903 \\ ${ }^{b}$ Rhode Island Training School, 300 New London Avenue, Cranston, RI, 02920 \\ cUniversity of Rhode Island, 2 Chafee Road, Kingston, RI 02881 \\ dVeterans Administration Medical Center, 830 Chalkstone Avenue, Providence, RI 02908
}

\begin{abstract}
Adolescents have been reported to be less motivated to engage and remain in substance abuse treatment than adults. When they appear motivated, it is often due to external motivators such as family pressure or court mandated treatment. The purpose of this study was to determine if adolescents' motivation to change alcohol use was related to treatment engagement while incarcerated and alcohol use after release. Participants $(\underline{N}=114)$ were youth in a state correctional facility in the Northeast and included adolescents who engaged in at least monthly drinking. Motivation to change alcohol use was measured by the Alcohol Ladder (AL), and treatment engagement was measured by the Treatment Participation Questionnaire (comprised of positive and negative treatment engagement). Measures were administered at baseline, 2 month in facility follow up, and 3 months post release follow up. Analysis indicated acceptable test-retest stability $(r=.388, \mathrm{p} \leq .001)$. The AL at 3 months post release significantly predicted quantity and frequency of alcohol use after release. The AL at baseline also significantly predicted positive and negative treatment engagement at 2 months into incarceration (i.e., 2 month in facility follow up) indicating predictive validity. These results suggest that the AL is a reliable, valid, and useful instrument for incarcerated youth.
\end{abstract}

\section{Keywords}

incarcerated youth; Contemplation Ladder; motivation to change; alcohol use; adolescent; treatment engagement

\footnotetext{
(C) 2010 Elsevier Ltd. All rights reserved.

Corresponding author Mary Clair, PhD University of Rhode Island Cancer Prevention Research Center 2 Chafee Rd Kingston, RI 02881 Phone 401-874-4261 Fax 401-874-5562 mclair@uri.edu.

Publisher's Disclaimer: This is a PDF file of an unedited manuscript that has been accepted for publication. As a service to our customers we are providing this early version of the manuscript. The manuscript will undergo copyediting, typesetting, and review of the resulting proof before it is published in its final citable form. Please note that during the production process errors may be discovered which could affect the content, and all legal disclaimers that apply to the journal pertain.
} 


\section{Introduction}

\subsection{Background}

Alcohol use continues to be a prevalent problem among incarcerated youth (Stein et al., 2006). Almost $90 \%$ of incarcerated male youth report alcohol use (Lebeau-Craven et al., 2003) and over $25 \%$ of juvenile detainees meet diagnostic criteria for alcohol use disorder (Teplin, Abram, McClelland, Dulcan, \& Mericle, 2002). Moreover, alcohol use lifetime prevalence rate is $49 \%$ in the juvenile justice population (Aarons, Brown, Hough, Garland, \& Wood, 2001). In contrast, Roberts and colleagues (Roberts, Roberts, \& Xing, 2007) found a $2.9 \%$ prevalence rate for the past year in youth in a metropolitan area. The high use of alcohol among incarcerated youth not only has individual negative consequences, but also societal implications as it is well documented that alcohol and/or drugs are frequently used by adolescents prior to the commission of a crime (National Institute of Justice [NIJ], 1997; 2003). An investigation of substance use by Juvenile Justice involved adolescents found that those arrested in the past year were twice as likely to have used alcohol as compared to adolescents who were not arrested in the last year (National Center on Addiction and Substance Abuse at Columbia University, 2004). In general, adolescents have been reported to be less motivated to engage and remain in substance abuse treatment as compared to adults (Melnick, DeLeon, Hawke, Jainchill, \& Kressel, 1997). When they appear motivated, it is often due to external motivators such as family pressure and/or court mandated treatment (Breda \& Heflinger, 2004). The Stages of Change (SOC), a component of the Transtheoretical Model (TTM) developed by Prochaska and DiClimente (1983), has a long history of use with alcohol and substance abusing adults (e.g., Bertholet, Cheng, Palfai, Samet, \& Saitz, 2009; Edens \& Willoughby, 2000; Ledgerwood \& Petry, 2006) and more recently has been used to assess motivation to change in adolescent substance users (Breda \& Heflinger, 2004; Callaghan et al., 2005; Greenstein, Franklin, \& McGuffin, 1999). Its use has also extended to incarcerated adult populations to assess motivation for smoking cessation in incarcerated males (Cropsey \& Kristeller, 2003) and for substance use in incarcerated females (El-Bassel et al., 1998). Despite the extension of the SOC from adults to adolescents in general, the SOC has rarely been applied to incarcerated youth. Instead, authoritarian approaches such as Scared Straight programs continue to be used to promote external motivation to decrease delinquent behaviors even though, in general, these types of programs are not successful and some have been shown to actually increase recidivism (Melnick et al., 1997). However, the past few years have evidenced an emergence in the use of SOC with this population (Cohen, Glaser, Calhoun, Bradshaw, \& Petrocelli, 2005; Slavet et al., 2006).

\subsection{Stages of Change (SOC)}

The Stages of Change (SOC) has tremendously influenced the conceptualization and treatment of several health-related disorders. Although this paradigm was conceptualized initially for smoking cessation (DiClemente et al., 1991; Velicer et al., 1995), it has since been applied to different behaviors including multiple behavior change (Prochaska et al., 2005; Prochaska et al., 2008).

The basic tenet of SOC suggests that individuals vary in their stage of readiness to change. The five stages of change are exclusive, dynamic, and cyclical and include the precontemplation stage, the contemplation stage, the preparation stage, the action stage, and the maintenance stage.

\subsection{Measures}

As a result, several types of instruments have been developed to measure SOC such as algorithms (Crittenden, Manfredi, Lacey, Warnecke, \& Parsons, 1994), rating scales 
(URICA; McConnaughy, DiClemente, Prochaska, \& Velicer, 1989) and visual analogs (Contemplation Ladder (CL); Biener \& Abrams, 1991). These instruments have demonstrated good concurrent and convergent validity (Amodei \& Lamb, 2004; Stephens, Cellucci, \& Gregory, 2004). The simplicity of visual analogs such as the CL may make it preferable in some settings and with some populations.

The CL is a Stages of Change (SOC; Prochaska and DiClemente, 1983, 1984) visual analog comprised of 10 rungs and associated anchor statements. Consistent with the SOC, the CL measures an individual's motivation to make a behavior change along a continuum of stages (i.e., pre-contemplation, contemplation, preparation, action, and maintenance). It has been used assess motivation in adult substance users (Hogue, Dauber, \& Morgenstern, 2010) and has been widely used for adult smoking cessation in a variety of populations including emergency department smokers, alcohol dependent patients, and pregnant smokers (Abrams, Herzog, Emmons, \& Linnan, 2000; Amodei \& Lamb, 2004; Bernstein et al., 2008; Herzog, Abrams, Emmons, \& Linnan, 2000; Hutchison, Stevens, \& Collins, 1996; Joseph, Lexau, Willenbring, Nugent, \& Nelson, 2004; Martin, Rohsenow, MacKinnon, Abrams, \& Monti, 2006). It has also been used with incarcerated adolescent substance users (Slavet et al., 2006) and adolescent substance users exposed to a tobacco program (McDonald, Roberts, \& Descheemaeker, 2000).

Several studies have shown the CL has good convergent and concurrent validity with other instruments used to measure SOC. A study of adult smokers reported support for convergent and concurrent validity of the CL and the URICA and suggested that the simplicity of the CL may make it an appropriate option in certain clinical settings (Amodei \& Lamb, 2004). A study of adolescent smokers comparing the CL, the URICA, and the Crittenden algorithm found the CL and the Crittenden algorithm to have good concurrent validity as compared to the concurrent validity of the other measures (Stephens et al., 2004).

One such population in which the CL may have utility is incarcerated youth. A recent study found concurrent and predictive validity for the Marijuana Ladder (ML), a modified version of the CL, in a sample of incarcerated youth (Slavet et al., 2006). The ML at baseline was correlated with marijuana use variables at baseline, and the ML at post release follow up was related to marijuana use variables at follow up. The ML was also related to treatment engagement at baseline and at the 2 month in facility follow up. Moreover, the ML at baseline significantly predicted treatment engagement during incarceration and marijuana use after release.

Despite the high prevalence of alcohol use in incarcerated youth, psychometric properties for CL with respect to alcohol use have not been established. The concurrent and predictive validity of the ML (an adaptation of the CL) with marijuana-using incarcerated youth suggests the Alcohol Ladder (AL, a modified CL for alcohol use) may also be applicable in this setting. Furthermore, the simplicity and ease of administration of the AL may be more palatable for this population as compared to longer and more complicated instruments.

\subsection{Rationale and Hypotheses}

Although the CL has sound psychometric properties in other populations, psychometric properties for incarcerated youth who use alcohol have not been established. The purpose of the current study was to determine if adolescents' motivation to change alcohol use was related to treatment engagement while incarcerated and alcohol use after release. To these ends, we hypothesized that during incarceration motivation to decrease alcohol use would be associated significantly with treatment engagement and higher motivation at post release follow up would be negatively related to alcohol use variables at post release follow up. 


\section{Methods}

\subsection{Participants}

Participants in the study $(\underline{\mathrm{N}}=114)$ were incarcerated youth in a state correctional facility in the Northeast region. At this facility, the only juvenile correctional facility in the state, approximately 1,000 to 1,200 youths annually are detained pending adjudication and approximately $50 \%$ of those youth are subsequently incarcerated. Length of sentences for these youths ranged from a few weeks to several years. Crimes committed by the youth in the facility ranged from status offenses to murder, and the annual recidivism rate for the facility is approximately $35 \%$. A multidisciplinary team provided treatment to these youth which included medical, dental, psychiatric, psychological, and school-based services.

\subsection{Procedures}

2.2.1 Overview-The participants in the current study were assessed as part of an ongoing randomized clinical trial (Slavet et al., 2006; Stein et al., 2006). Briefly, for the larger clinical trial, the initial baseline assessment battery was completed shortly after incarceration. Following assessment, participants were randomly assigned to one of two treatment conditions, Relaxation Therapy (RT; 48\%) or Motivational Interviewing (MI; $52 \%$ ). Each treatment condition was delivered during one session at baseline (90 minutes) and one follow up booster session (60 minutes). The MI intervention was comprised of 4 components: establishing rapport, assessing motivation to change alcohol and marijuana use, enhancing motivation to change, and establishing goals to aid in making changes. The RT intervention was comprised of muscle relaxation and meditation as a behavior management technique. A follow up assessment was conducted after participants had been incarcerated for 2 months and a final follow up assessment was performed in the community 3 months after release from the facility.

2.2.2 Screening and consent-Immediately upon incarceration, youth were identified as potential participants if they were between 14 and 19 years of age, and if they were to be sentenced at the facility between 4 and 12 months. Youth assent and guardian consent were obtained by trained research assistants, and the youth and their guardians were informed that the information obtained during each assessment was confidential with the exception of plans to harm self or others, reports of child abuse, and plans for escape. Institutional Review Board approval was obtained for all procedures from Brown University.

Potential participants were adjudicated between April, 2001 to March, 2006, and adolescents were eligible in the larger randomized clinical trial if they met any of the following substance use screening criteria: 1 ) in the year prior to incarceration they a) used marijuana or drank regularly (at least monthly), or b) if they drank 5 or more standard drinks for boys or 4 or more standard drinks for girls on any occasion; 2) they used marijuana or drank in the 4 weeks before the offense for which they were incarcerated; 3 ) they used marijuana or alcohol in the 4 weeks prior to incarceration. The final sample for the larger trial was $\underline{N}=189$.

One thousand ninety-six adolescents were initially screened, and 869 were determined ineligible for the study during record review (e.g. did not meet age and/or sentence length criteria, guardian could not be located for consent). Of the remaining 227 adolescents approached for the study, 18 did not meet substance use screening criteria (see above criteria), 8 had a language barrier, and 6 more declined participation in the study. Of those 195 , four adolescents dropped out of the study prior to completing the initial assessment or treatment and two participants were lost during the follow-up period. Of the remaining 189, 181 were re-interviewed at 3-month follow-up; five could not be located for follow-up after 
release from the facility, and three adolescents withdrew from the study prior to completion of the 3-month follow-up.

For the current study, we selected adolescents who drank at least monthly ( $\mathrm{N}=114)$. Timeline Follow Back variables were quantified into alcohol quantity (average number of alcohol drinks consumed per week over the past 3 months), alcohol frequency (number of days alcohol was consumed in the past 3 months), and alcohol intensity (average number of alcohol drinks consumed per drinking day).

To analyze the Timeline Follow Back variables (i.e., quantity, frequency, intensity) at 3 months follow up after release, the adolescents had to reside in a non-controlled environment for at least 45 days. About $9 \%$ of the sample was in a controlled environment.

2.2.3 Community tracking-In order to collect follow up data in the community, multiple sources of contact information were documented prior to release such as addresses, telephone numbers, pager numbers, employer address/phone numbers, shifts at work, school addresses/phone numbers, driver's license numbers, case workers, probation officers, and two family members and/or friends. Participants signed a letter to each contact that explained they were participating in a research project and had given permission for the contact to provide the project staff with information with which to locate him/her.

Prior to release from the facility, the final follow up session was scheduled, and appointment cards with the date, time, and location of the appointment were given to the teen.

Additionally, the telephone number of the project staff was provided. Reminder calls were made one week prior to the appointment by the research staff, and reminder letters were mailed when participants did not have a phone.

2.2.4 Assessments-The baseline assessment occurred soon after adjudication, and this 90 minute interview was conducted by a Bachelor's level or Master's level research study staff member. Interviewers initially received 20 hours of training and subsequently received individual supervision as needed (usually weekly), and 1 hour of group supervision per week. All assessment data were reviewed by a Doctoral level or a Master's level research study staff member and periodic in-vivo assessment observations were conducted by a Doctoral level staff member. Snacks were provided to the participants during the baseline and 2 month in facility follow up and $\$ 50$ gift certificates were given for the post release follow up assessments. An additional $\$ 10$ gift certificate was given to the participants if the post release assessments were completed on time (within one week). Follow up assessment procedures were identical to the baseline assessment procedures with the exception of sociodemographic data collection and environment (i.e., socio-demographic data were not collected again, and the final follow up assessment was conducted in the community). At each assessment, youth were reminded of the federal Certificate of Confidentiality (COC) to enhance accuracy of self-report. The COC assures youth that their information remains private (with the exception of the standard limits of confidentiality) and is not shared with anyone, including family and department of correction personnel.

\subsection{Measures}

2.3.1 Background Questionnaire (BGQ)-Socio-demographic data were collected at baseline and included age, gender, ethnicity, number of school years completed, and parent/ guardian educational level.

2.3.2 Timeline Follow Back (TLFB)—The Timeline Follow Back is a calendar based measure that assesses participants' substance use over a specified period of time (Sobell \& Sobell, 1992). A 90 day TLFB was collected at baseline and post release follow up via 
interview with a research study staff member. Three TLFB variables were used: 1) alcohol quantity (average number of alcohol drinks consumed per week over the past 3 months), 2) alcohol frequency (number of days alcohol was consumed in the past 3 months), and 3) alcohol intensity (average number of alcohol drinks consumed per drinking day).

2.3.3 Treatment Participation Questionnaire for incarcerated youth (TPQ)-The TPQ assesses attitudes and behaviors towards individual, group, and milieu substance treatment. The Treatment Participation Questionnaire Teen (TPQT) contains 21 items at baseline and 26 items at follow up (Stein et al., 2004; Stein et al., 2006). The Treatment Participation Questionnaire Social Worker (TPQM) consists of 15 items. The TPQT has two components, positive (TPQTP) and negative (TPQTN) engagement scales. The TPQM has one component, a negative engagement scale, and both measures have demonstrated validity. Both measures are rated on a Likert scale $(1=$ disagree strongly to $6=$ agree strongly). The TPQT includes items such as, "I think a lot about the good and bad things about substance use" (positive engagement), and "I like to joke in treatment when they begin discussing substance use" (negative engagement). Youth completed the TPQT at baseline and again approximately 2 months into treatment. The TPQM was completed by social workers about 2 months into treatment (there was no social worker version completed at baseline).

2.3.4 Alcohol Ladder ( $\mathbf{A L}$ )-The Alcohol Ladder (AL) is an adapted version of the Contemplation Ladder (CL; Biener \& Abrams, 1991). The CL is a Stages of Change (SOC; Prochaska and DiClemente, 1983) visual analog comprised of 10 rungs and 5 anchor statements. Consistent with the SOC, the CL measures an individual's motivation to make a behavior change along a continuum of stages (i.e., pre-contemplation, contemplation, preparation, action, and maintenance). Similarly, the AL is a visual analog comprised of 10 rungs; however, instead of 5 anchor statements, each rung is accompanied by a corresponding statement. Adaptations were made to the AL so the corresponding statements for each rung were applicable for incarcerated youth without access to alcohol such as, "After release, I definitely plan to change my alcohol use, and I'm almost ready to make some plans about how to change" (see Appendix).

The instructions for the CL are: "Each rung on this ladder represents where various smokers are in their thinking about quitting. Circle the number that best represents where you are now" (Biener \& Abrams, 1991). Similar to these instructions, the instructions for the AL are: "Each rung of this ladder shows where a person might be in thinking about changing their drinking. Select the number that best matches where you are now." In the current study, the participants used the 10 rungs to indicate where they were along the SOC continuum (see Appendix). The AL was completed at baseline, at 2 months into incarceration (i.e., 2 month in facility follow up), and 3 month post release follow up. The AL remained the same for each assessment; however, the wording for the post release follow up in the community differed slightly to reflect access to alcohol.

\section{Results}

\subsection{Data cleaning}

Prior to analyses, all variables were examined for distributional properties. Two alcohol use indices were log transformed to correct for skewness and kurtosis.

\subsection{Participant Characteristics}

At the baseline assessment, 114 participants (a sub sample of the 189 total participants in the clinical trial) reported drinking alcohol on a monthly basis or more. The sample was 
primarily male $(87 \%)$ and the mean age at baseline was $17.29(\mathrm{SD}=1.02)$. Forty percent of the sample identified as Caucasian, 27\% identified as Hispanic/Latino, 21\% identified as African American, 5\% identified as Asian American, 2\% identified as Native American, and $5 \%$ identified as Other. The average age for first use of alcohol was $12.09(\mathrm{SD}=2.99)$, and the average number of times previously detained was 2.95 times $(\mathrm{SD}=3.76)$.

We examined baseline differences between participants in the larger trial and the sub sample used for this study. The sub sample of monthly drinkers was older $(\mathrm{M}=17.29, \mathrm{SD}=1.02)$ than non-monthly drinkers $(\mathrm{M}=16.83, \mathrm{SD}=1.21 ; t(179)=-2.72, \mathrm{p}=.007)$ was at a younger age for having their first drink $(\mathrm{M}=12.09, \mathrm{SD}=2.99 ; t(171), 2.42, \mathrm{p}=.017)$ than non-monthly drinkers $(\mathrm{M}=13.22, \mathrm{SD}=2.77)$, and more monthly drinkers were Caucasian than non-monthly drinkers $\left(\chi^{2}(3,181)=16.844, p>.001\right)$. No significant differences were found for number of times previously detained, age of first use of marijuana or other drugs, and gender.

Based on the criteria for the Structured Clinical Interview for DSM-IV-Patient version (SCID; First, Spitzer, Gibbon, \& Williams, 1995), 49\% of the participants met diagnostic criteria for alcohol dependence, 33\% met criteria for alcohol abuse, and 18\% did not meet any diagnostic criteria for any alcohol diagnosis. Regarding lifetime drug use, 113 of the 114 participants reported using marijuana and 73 participants reported using other illegal drugs. The average age of first use was $12.24(\mathrm{SD}=2.11)$ and $14.97(\mathrm{SD}=1.69)$ respectively.

At 2 month in facility follow up, one youth was unavailable for assessment due to an early release resulting in $\underline{N}=113$. At 3 months follow up after release, 7 youth were lost to follow up resulting in $\underline{N}=107$. Ten youth were in a controlled environment for more than 45 days during Timeline Followback assessment and were removed from analyses (approximately $9 \%$ ). Thus, the sample decreased to $\mathrm{N}=97$ for quantity (average number of alcohol drinks consumed per week over the past 3 months) and frequency (number of days alcohol was consumed in the past 3 months) variables. Regarding intensity (average number of alcohol drinks consumed per drinking day), 21 adolescents did not have a drinking day, therefore the sample decreased to $\underline{\mathrm{N}}=76$ for the intensity variable.

The means and standard deviations for the $\mathrm{AL}$ at three time points are reported in Table 1 along with the percentage of youth who endorsed each SOC at three time points. Table 2 provides the means and stand deviations for alcohol consumption at baseline and 3 month follow-up.

\subsection{Reliability}

To investigate reliability of the $\mathrm{AL}$, the $\mathrm{AL}$ at baseline was correlated with the $\mathrm{AL}$ at the 2 month-in-facility assessment and a significant correlation was found $(r=.388, \mathrm{p} \leq .001)$.

\subsection{Concurrent Validity and Construct Validity}

3.4.a Simple Correlations-To investigate concurrent validity (i.e., correlation of a measure with performance on another measure or criterion at the same point in time; Kazdin, 1998) and construct validity (i.e., extent to which the measure has been shown to asses the construct of interest; Kazdin, 1998), the AL measured at baseline was correlated with the TLFB alcohol use indices (i.e., quantity, frequency, and intensity) and treatment engagement indices (i.e., TPQTP, TPQTN, and TPQM) measured at baseline. Similarly, the AL measured at the 3 month post release follow up was correlated with the TLFB alcohol use indices measured at the 3 month post release follow up. Lastly, the AL measured 2 months into incarceration was correlated with treatment engagement measured 2 months into incarceration. To reduce the likelihood of a Type 1 error, the Bonferroni correction (Howell, 1992) was used $(.05 / 3=.017 ; .05 / 2=.025)$. As Table 3 indicates, none of the alcohol 
use indices measured at baseline were significantly correlated with the AL measured at baseline. However, all of the alcohol use indices measured at the 3 month post release follow up were significantly negatively correlated with the AL at the 3 month post release follow up.

As indicated in Table 3, the AL measured at baseline was significantly positively correlated with teen self-report of positive treatment engagement in substance abuse treatment at baseline and significantly negatively correlated with teen self-report of negative treatment engagement in substance abuse treatment at baseline. The AL at the 2 month in facility assessment was also significantly positively correlated with teen self report of positive treatment engagement in substance abuse treatment at the 2 month in facility assessment. Conversely, the AL at 2 months into treatment was not correlated with teen self report of negative treatment engagement in substance abuse treatment or with the social worker's report of the teen's treatment engagement at 2 months into treatment.

3.4.b Regression Models-Three hierarchical multiple regressions were conducted to assess whether the AL at 3 months post release was associated with alcohol use indices (i.e., quantity, frequency, and intensity) at 3 months post release independent of the influence of age, alcohol use at baseline, randomized treatment assignment, and AL at baseline. Age, alcohol use at baseline, treatment assignment, and AL at baseline were entered on step 1, and $\mathrm{AL}$ at 3 month post release was entered on step 2. As Table 4 indicates, the AL at 3 month post release significantly predicted quantity and frequency of alcohol use at 3 month post release. However, the AL at 3 month post release did not significantly predict intensity of alcohol use at 3 month post release (see Table 4).

\subsection{Predictive Validity}

To determine how well the AL predicts treatment engagement, three hierarchical multiple regressions were conducted to assess whether $\mathrm{AL}$ at baseline was associated with treatment engagement indices (i.e., teen positive treatment engagement, teen negative treatment engagement, and social worker's rating of negative treatment engagement) at 2 months into incarceration independent of the influence of age, baseline alcohol use, and randomized treatment assignment. Age, quantity of alcohol use at baseline, and treatment assignment were entered on step 1, and the AL at baseline was entered on step 2. For this analysis, we chose to control for quantity of alcohol use at baseline instead of treatment engagement at baseline since we were interested in investigating if the AL could significantly predict treatment engagement while holding quantity of alcohol use at baseline constant. Table 5 indicates the AL at baseline significantly predicted teen positive treatment engagement and teen negative treatment engagement at 2 months into incarceration but not social worker's rating of negative treatment engagement.

\section{Discussion}

To our knowledge, this is the first study to investigate the utility of a modified version of the Contemplation Ladder, the Alcohol Ladder (AL), in a sample of incarcerated youth. For this sample of adolescents who drank at least monthly, the AL was found to be reliable and have good concurrent, construct, and predictive validity. The $\mathrm{AL}$ at 3 month post release predicted the average number of alcoholic drinks they consumed per week over the past 3 months (quantity) and the number of days alcohol was consumed in the past 3 months (frequency) at 3 month post release but not the average number of alcohol drinks consumed per drinking day (intensity) after controlling for age, baseline alcohol use, treatment assignment, and baseline AL. These results indicate (see Table 3) that for these adolescents, motivation to change their alcohol consumption was concurrently related to the number of 
days alcohol was consumed in the past 3 months (frequency) and the average number of alcohol drinks consumed per week over the past 3 months (quantity), but that motivation to change drinking was not predictive of the average number of alcohol drinks consumed per drinking day (intensity). One possible explanation is the influence of peers during drinking episodes. Youth's motivation to change their drinking may be high as evidenced by the quantity and frequency variables, but on the days that they drink (intensity), they may drink more than intended due to peer influence. Other findings indicate that best friend's drinking behavior is related cross-sectionally and longitudinally to an adolescent's drinking (Bot, Engels, Knibbe, \& Meeus, 2005), and for adolescent males, having a best friend that drinks heavily increases one's risk for a heavy drinking trajectory (Van Der Vorst, Vermulst, Meeus, Deković, \& Engels, 2009). The AL at baseline did not correlate with alcohol use at baseline. One possible explanation is that the $\mathrm{AL}$ at baseline assesses current interest in reducing alcohol use while the TLFB assesses alcohol use prior to incarceration. Their current incarceration may impact on their current motivation to change alcohol use as reflected by the AL.

The AL at 2 months into incarceration was not correlated with teen negative treatment engagement nor was it correlated with social worker's rating of teen negative treatment engagement. The lack of concurrent validity with teen negative treatment engagement at 2 months into incarceration may be due to teens becoming negative about their situation in general (including treatment) as time progresses (Stein et al., 2006) although they still may wish to reduce alcohol use.

Although the AL predicted teen's positive rating of treatment engagement and teen's negative rating of treatment engagement at 2 months into incarcerations, it did not predict social worker's rating of treatment engagement at 2 months into incarceration (see Table 5). One plausible explanation is that social worker ratings of negative treatment engagement are not based on observation of the youth in substance abuse treatment but rather based on the social worker's overall observation, knowledge, and impression of the youth. Collateral data are important for this population; however, perhaps more accurate substance specific collateral information may be obtained from the substance abuse group therapists. Given the overall findings, the AL shows promise as a tool to measure motivation to change in incarcerated youth.

Motivation to change is an important construct to measure in incarcerated youth. Substance abuse treatment is often court-mandated and identifying which youth are motivated to change their substance use behavior can have treatment implications. For example, youth who indicate they are ready to change their use may be prepared and benefit from a skills based relapse prevention program whereas youth who are not ready to change their use may benefit from first receiving a motivational enhancement intervention.

This study was conducted primarily with incarcerated male (87\%) youth, thus these results may not be generalizable to outpatient settings and may have more limited applicability to female incarcerated youth. The generalizability of this study may also be limited because of the differences found between study participants and non-participants for race and age of first alcohol use. Results may be more applicable to Caucasians and persons beginning alcohol use at a relatively young age. Also, the sample of 114 adolescents is relatively small and is limited to one juvenile correctional facility in the Northeastern United States. A more heterogeneous sample may have yielded different results, thus replication of this study is needed before any generalizations about incarcerated juveniles can be made. Another limitation of this study is the reliance on self-report data as these youth may be over or under reporting their alcohol consumption (i.e., quantity, frequency, and intensity) and their motivation to change their alcohol consumption (i.e., AL scores). Several strategies were 
used to assist respondents in being honest with respect to self-reported behaviors. All interviews were conducted in private, youths were reminded of the federal Certificate of Confidentiality that assures privacy of information (not withstanding the usual limits of confidentiality), they knew collateral reports of behavior (from staff and record review) and biological samples would be accessed, and they were periodically reminded that no information would be shared with parents or facility staff. Collateral sources are often used in conjunction with self-report measures to assess the reliability of self-report data.

However, Dennis and colleagues (Dennis et al., 2002) found that collateral sources were often unaware of their adolescents' substance use. Moreover, Babor and colleagues (Babor, Steinberg, \& Anton, 2000) indicated that biological indicators corresponded to self-report data thus suggesting these additional measurements are not warranted.

Despite these limitations, the Alcohol Ladder appears to be a useful measure with incarcerated youth. With limited time and resources, facilities that serve these youth may appreciate the ease of administration of the AL. Additionally, with its concurrent and predictive validity, the AL may have important treatment and discharge planning implications. Future studies may want to address the aforementioned limitations as well as investigate any difference between incarcerated adults and incarcerated youth on the AL.

\section{Appendix: Rungs of the Alcohol Ladder}

\section{Pre-contemplation stage}

1) I enjoy drinking and have decided I'll never change it. I have no interest in changing the way I drink.

2) I never think about changing the way I drink, and I have no plans to change.

\section{Contemplation stage}

3) I rarely think about changing the way I drink, and I have no plans to change it.

4) I sometimes think about changing the way I drink, but I have no plans to change it.

5) I often think about changing my drinking but I have no plans to change it.

6) After release, I definitely plan to change my alcohol use, but I'm not ready to make any plans about how to change.

\section{Preparation stage}

7) After release, I definitely plan to change my alcohol use, and I'm almost ready to make some plans about how to change.

8) I plan on drinking after release. But I'll make some changes, like cutting back on the amount of alcohol I use.

\section{Action stage}

9) I have changed my drinking, but I still worry about slipping back. So I need to keep working on the changes I've made.

\section{Maintenance stage}

10) I have changed my drinking and will never go back to the way I drank before. 


\section{References}

Aarons GA, Brown SA, Hough RL, Garland AF, Wood PA. Prevalence of adolescent substance use disorders across five sectors of care. J Am Acad Child Adolesc Psychiatry. 2001; 40:419-426. [PubMed: 11314567]

Abrams DB, Herzog TA, Emmons KM, Linnan L. Stages of change versus addiction: A replication and extension. Nicotine Tob Res. 2000; 2(3):223-229. [PubMed: 11082822]

Amodei N, Lamb RJ. Convergent and concurrent validity of the Contemplation Ladder and URICA scales. Drug Alcohol Depend. 2004; 73:301-306. [PubMed: 15036552]

Babor TF, Steinberg K, Anton R. Talk is cheap: Measuring drinking outcomes in clinical trials. J Stud Alcohol. 2000; 61(1):55-63. [PubMed: 10627097]

Bernstein S, Boudreaux ED, Cabral L, Cydulka RK, Schwegman D, Larkin GL, et al. Nicotine dependence, motivation to quit, and diagnosis among adult emergency department patients who smoke: A national survey. Nicotine Tob Res. 2008; 10(8):1277-1282. [PubMed: 18686174]

Bertholet N, Cheng DM, Palfai TP, Samet JH, Saitz R. Does readiness to change predict subsequent alcohol consumption in medical inpatients with unhealthy alcohol use? Addict Behav. 2009; 34(8): 636-640. [PubMed: 19428189]

Biener L, Abrams DB. The Contemplation Ladder: Validation of a measure of readiness to consider smoking cessation. Health Psychol. 1991; 10(5):360-365. [PubMed: 1935872]

Bot SM, Engels RCME, Knibbe RA, Meeus WHJ. Friend's drinking behaviour and adolescent alcohol consumption: The moderating role of friendship characteristics. Addict Behav. 2005; 30(5):929947. [PubMed: 15893090]

Breda C, Heflinger CA. Predicting incentives to change among adolescents with substance abuse disorder. Am J Drug Alcohol Abuse. 2004; 30(2):251-267. [PubMed: 15230075]

Callaghan RC, Hathaway A, Cunningham JA, Vettese LC, Wyatt S, Taylor L. Does stage-of-change predict dropout in a culturally diverse sample of adolescents admitted to inpatient substance-abuse treatment? A test of the Transtheoretical Model. Addict Behav. 2005; 30:1834-1847. [PubMed: 16111832]

Cohen PJ, Glaser BA, Calhoun GB, Bradshaw CP, Petrocelli JV. Examining readiness to change: A preliminary evaluation of the University of Rhode Island Change Assessment with incarcerated adolescents. Meas Eval Counsel Dev. 2005; 38:45-62.

Crittenden KS, Manfredi C, Lacey L, Warnecke R, Parsons J. Measuring readiness and motivation to quit smoking among women in public health clinics. Addict Behav. 1994; 19(5):497-507. [PubMed: 7832008]

Cropsey KL, Kristeller JL. Motivational factors related to quitting smoking among prisoners during a smoking ban. Addict Behav. 2003; 28(6):1081-1093. [PubMed: 12834652]

Dennis M, Titus JC, Diamond G, Donaldson J, Godley SH, Tims FM, et al. The Cannabis Youth Treatment (CYT) experiment: Rationale, study design and analysis plans. Addiction. 2002; 97:1634. [PubMed: 12460126]

DiClemente CC, Prochaska JO, Fairhurst SK, Velicer WF, Velasquez MM, Rossi JS. The process of smoking cessation: An analysis of precontemplation, contemplation, and preparation stages of change. J Consult Clin Psychol. 1991; 59(2):295-304. [PubMed: 2030191]

Edens JF, Willoughby FW. Motivational patterns of alcohol dependent patients: A replication. Psychol Addict Behav. 2000; 14(4):397-400. [PubMed: 11130158]

El-Bassel N, Schilling RF, Ivanoff A, Chen DR, Hanson M, Bidassie B. Stages of change profiles among incarcerated drug-using women. Addict Behav. 1998; 23(3):389-394. [PubMed: 9668936]

First, MB.; Spitzer, RL.; Gibbon, M.; Williams, JBW. Structured Interview for DSM-IV Axis I Disorders. Patient Edition (SCID-IV-P, Version 2.0). Biometrics Research Department, Psychiatric Institute; New York: 1995.

Greenstein DK, Franklin ME, McGuffin P. Measuring motivation to change: An examination of the University of Rhode Island Change Assessment Questionnaire (URICA) in an adolescent sample. Psychother Theory Res Pract Training. 1999; 36(1):47-55.

Herzog TA, Abrams DB, Emmons KM, Linnan L. Predicting increases in readiness to quit smoking: A prospective analysis using the contemplation ladder. Psychol Health. 2000; 15(3):369-382. 
Hogue A, Dauber S, Morgenstern J. Validation of a contemplation ladder in an adult substance use disorder sample. Psychol Addict Behav. 2010; 24(1):137-144. [PubMed: 20307121]

Howell, D. Statistical methods for psychology. 3rd ed. PWS-Kent; Boston: 1992.

Hutchison KE, Stevens VM, Collins FL. Cigarette smoking and the intention to quit among pregnant smokers. J Behav Med. 1996; 19(3):307-316. [PubMed: 8740471]

Joseph A, Lexau B, Willenbring M, Nugent S, Nelson D. Factors associated with readiness to stop smoking among patients in treatment for alcohol use disorder. Am J Addict. 2004; 13(4):405-417. [PubMed: 15370939]

Lebeau-Craven R, Stein L, Barnett NP, Colby SM, Smith JL, Canto AL. Prevalence of alcohol and drug use in an adolescent training facility. Subst Use Misuse. 2003; 38(7):825-834. [PubMed: 12801144]

Ledgerwood D,M, Petry N,M. Does contingency management affect motivation to change substance use? Drug Alcohol Depend. 2006; 83(1):65-72. [PubMed: 16310974]

Martin RA, Rohsenow DJ, MacKinnon SV, Abrams DB, Monti PM. Correlates of motivation to quit smoking among alcohol dependent patients in residential treatment. Drug Alcohol Depend. 2006; 83(1):73-78. [PubMed: 16314049]

McConnaughy EA, DiClemente CC, Prochaska JO, Velicer WF. Stages of change in psychotherapy: A follow up report. Psychother Theory Res Pract Training. 1989; 26(4):494-503.

McDonald CA, Roberts S, Descheemaeker N. Intentions to quit smoking in substance-abusing teens exposed to a tobacco program. J Subst Abuse Treat. 2000; 18(3):291-308. [PubMed: 10742645]

Melnick G, DeLeon G, Hawke J, Jainchill N, Kressel D. Motivation and readiness for therapeutic community treatment among adolescents and adult substance abusers. Am J Drug Alcohol Abuse. 1997; 23(4):485-506. [PubMed: 9366969]

National Center on Addiction and Substance Abuse at Columbia University. Criminal neglect: Substance abuse, juvenile justice, and the children left behind. Columbia University; New York: 2004. from http://www.casacolumbia.org/Absolutenm/articlefiles/JJreport.pdf

National Institute of Justice. 1997 annual report on adult and juvenile arrestees. U.S. Department of Justice; Washington, DC: 1997.

National Institute of Justice. 2000 arrestee drug abuse monitoring: Annual report (NCJ 193013). U.S. Department of Justice; Washington, DC: 2003.

National Institute on Alcohol Abuse and Alcoholism. Helping Patients Who Drink Too Much: A Clinician's Guide. National Institutes of Health; Washington, DC: 2005. revised 2007(NIH Publication No. 07-3769)Also available online: http://www.niaaa.nih.gov/guide

Prochaska JO, Butterworth S, Redding CA, Burden V, Perrin N, Leo M, Flaherty-Robb M, Prochaska JM. Initial efficacy of MI, TTM tailoring and HRI's with multiple behaviors for employee health promotion. Preventive Medicine: An International Journal Devoted to Practice and Theory. 2008; 46(3):226-231.

Prochaska JO, DiClemente CC. Stages and processes of self-change of smoking: Toward an integrative model of change. J Consult Clin Psychol. 1983; 51(3):390-395. [PubMed: 6863699]

Prochaska JO, Velicer W,F, Redding C, Rossi JS, Goldstein M, DePue J, Greene GW, Rossi SR, Sun X, Fava JL, Laforge R, Rakowski W, Plummer BA. Stage-based expert systems to guide a population of primary care patients to quit smoking, eat healthier, prevent skin cancer, and receive regular mammograms. Preventive Medicine: An International Journal Devoted to Practice and Theory. 2005; 41(2):406-416.

Roberts RE, Roberts CR, Xing Y. Rates of DSM-IV psychiatric disorders among adolescents in a large metropolitan area. J Psychiatr Res. 2007; 41(11):959-967. [PubMed: 17107689]

Slavet JD, Stein LAR, Colby SM, Barnett NP, Monti PM, Golembeske C, et al. The Marijuana Ladder: Measuring motivation to change marijuana use in incarcerated adolescents. Drug Alcohol Depend. 2006; 83:42-48. [PubMed: 16289930]

Sobell, LC.; Sobell, MB. Timeline Follow Back: A technique for assessing self-reported alcohol consumption. In: Litten, RZ; Allen, JP., editors. Measuring alcohol consumption: Psychosocial and Biochemical Methods. Humana Press, Inc.; NJ: 1992. p. 41-72.

Stein, LAR.; Colby, SM.; Barnett, NP.; Monti, PM.; Golembeske, C.; Lebeau-Craven, R. An alcohol and drug abuse treatment participation questionnaire for incarcerated adolescents. Poster presented 
at the 27th Annual Scientific Meeting of the Research Society on Alcoholism; Vancouver, Ontario, Canada. June. 2004

Stein LAR, Colby SM, Barnett NP, Monti PM, Golembeske C, Lebeau-Craven R, et al. Enhancing substance abuse treatment engagement in incarcerated adolescents. Psychol Serv. 2006; 3(1):2534. [PubMed: 20617117]

Stephens S, Cellucci T, Gregory J. Comparing stage of change measures in adolescent smokers. Addict Behav. 2004; 29:759-764. [PubMed: 15135558]

Teplin LA, Abram KM, McClelland GM, Dulcan MK, Mericle AA. Psychiatric disorders in youth in juvenile detention. Arch Gen Psychiatry. 2002; 59:1133-1143. [PubMed: 12470130]

Van Der Vorst H, Vermulst AA, Meeus WHJ, Deković M, Engels RCME. Identification and prediction of drinking trajectories in early and mid-adolescence. Journal of Clinical Child and Adolescent Psychology. 2009; 38(3):329-341. [PubMed: 19437294]

Velicer WF, Fava JL, Prochaska JO, Abrams DB, Emmons KM, Pierce JP. Distribution of smokers by stage in three representative samples. Prev Med. 1995; 24(4):401-411. [PubMed: 7479632] 


\section{Research highlights}

- Measured motivation to change alcohol use and treatment engagement in incarcerated youth.

- Post release motivation predicted quantity and frequency of alcohol use after release.

- Motivation predicted positive and negative treatment engagement at 2 months into incarceration. 


\section{Table 1}

Descriptive statistics: means and standard deviations of the Alcohol Ladder at three time points and the percentage of youth who endorsed each SOC at three time points.

\begin{tabular}{lll}
\hline $\begin{array}{l}\text { Community } \\
\text { follow up }(\underline{\mathbf{N}}=\mathbf{1 0 7})\end{array}$ & $\begin{array}{l}\text { Baseline } \\
(\underline{\mathbf{N}=114})\end{array}$ & $\begin{array}{l}\text { 2 Month in facility } \\
\text { Follow up }(\underline{\mathbf{N}}=\mathbf{1 1 3})\end{array}$ \\
\hline $\begin{array}{c}\text { Mean (standard deviation) } \\
7.02(3.00)\end{array}$ & $6.42(2.75)$ & $6.94(2.49)$ \\
$\begin{array}{c}\text { Pre contemplation }(\%) \\
14.0\end{array}$ & 12.3 & 8.8 \\
$\begin{array}{c}\text { Contemplation }(\%) \\
20.6\end{array}$ & 28.1 & 20.4 \\
$\begin{array}{c}\text { Preparation }(\%) \\
25.2\end{array}$ & 36.0 & 45.1 \\
$\begin{array}{c}\text { Action }(\%) \\
11.2\end{array}$ & 14.0 & 15.0 \\
$\begin{array}{c}\text { Maintenance }(\%) \\
29.0\end{array}$ & 9.6 & 10.6 \\
\hline
\end{tabular}




\section{Table 2}

Descriptive statistics: means and standard deviations for alcohol consumption at baseline and 3 month followup.

\begin{tabular}{|c|c|c|}
\hline $\begin{array}{l}\text { month } \\
\text { up }(\underline{N}=107)\end{array}$ & $\begin{array}{l}\text { Baseline } \\
(\underline{N}=114)\end{array}$ & $\begin{array}{l}3 \\
\text { follow }\end{array}$ \\
\hline \multicolumn{3}{|l|}{ Mean (standard deviation) } \\
\hline $\begin{array}{l}\text { Quantity (average number of } \\
\text { alcohol drinks consumed per } \\
\text { week over the past } 3 \text { months) } \\
\text { (15.56) }\end{array}$ & $19.74(22.04)$ & 9.58 \\
\hline $\begin{array}{l}\text { Frequency (number of days } \\
\text { alcohol was consumed in the } \\
\text { past } 3 \text { months) } \\
(13.40)\end{array}$ & $25.34(21.87)$ & 10.65 \\
\hline $\begin{array}{l}\text { Intensity (average number of } \\
\text { alcohol drinks consumed per } \\
\text { drinking day) } \\
(6.56)\end{array}$ & $9.28(6.19)$ & 9.35 \\
\hline
\end{tabular}




\section{Table 3}

Correlations of the AL with Timeline Follow Back alcohol use indices (Quantity, Frequency, and Intensity) and Treatment Engagement at two different time points.

\begin{tabular}{|c|c|c|c|}
\hline Alcohol Ladder & Alcohol use indices & \multicolumn{2}{|c|}{ Correlation $(r)$} \\
\hline \multirow{3}{*}{ Baseline } & Quantity & \multicolumn{2}{|c|}{-.116} \\
\hline & Frequency & \multicolumn{2}{|c|}{-.150} \\
\hline & Intensity & \multicolumn{2}{|c|}{.040} \\
\hline \multirow{3}{*}{$\begin{array}{l}\text { Three month } \\
\text { post release } \\
\text { follow up }\end{array}$} & Quantity & \multicolumn{2}{|c|}{$-.450 *$} \\
\hline & Frequency & \multicolumn{2}{|c|}{$-.398^{*}$} \\
\hline & Intensity & \multicolumn{2}{|c|}{$-.202^{*}$} \\
\hline \multicolumn{4}{|l|}{$* \mathrm{p} \leq .017$} \\
\hline Alcohol Ladder & \multicolumn{2}{|c|}{ Treatment Engagement } & Correlations $(r)$ \\
\hline \multirow{2}{*}{ Baseline } & TPQTP & & $.407^{*}$ \\
\hline & TPQTN & & $-.367^{*}$ \\
\hline \multirow{3}{*}{$\begin{array}{l}\text { Two month } \\
\text { in facility } \\
\text { assessment }\end{array}$} & TPQTP & & $.309^{*}$ \\
\hline & TPQTN & & -.023 \\
\hline & TPQM & & .043 \\
\hline
\end{tabular}

Note: TPQT: teen's rating of positive treatment engagement; TPQTN: teen's rating of negative treatment engagement; TPQM: social worker's rating of negative treatment engagement

${ }^{*} \leq .001$. 

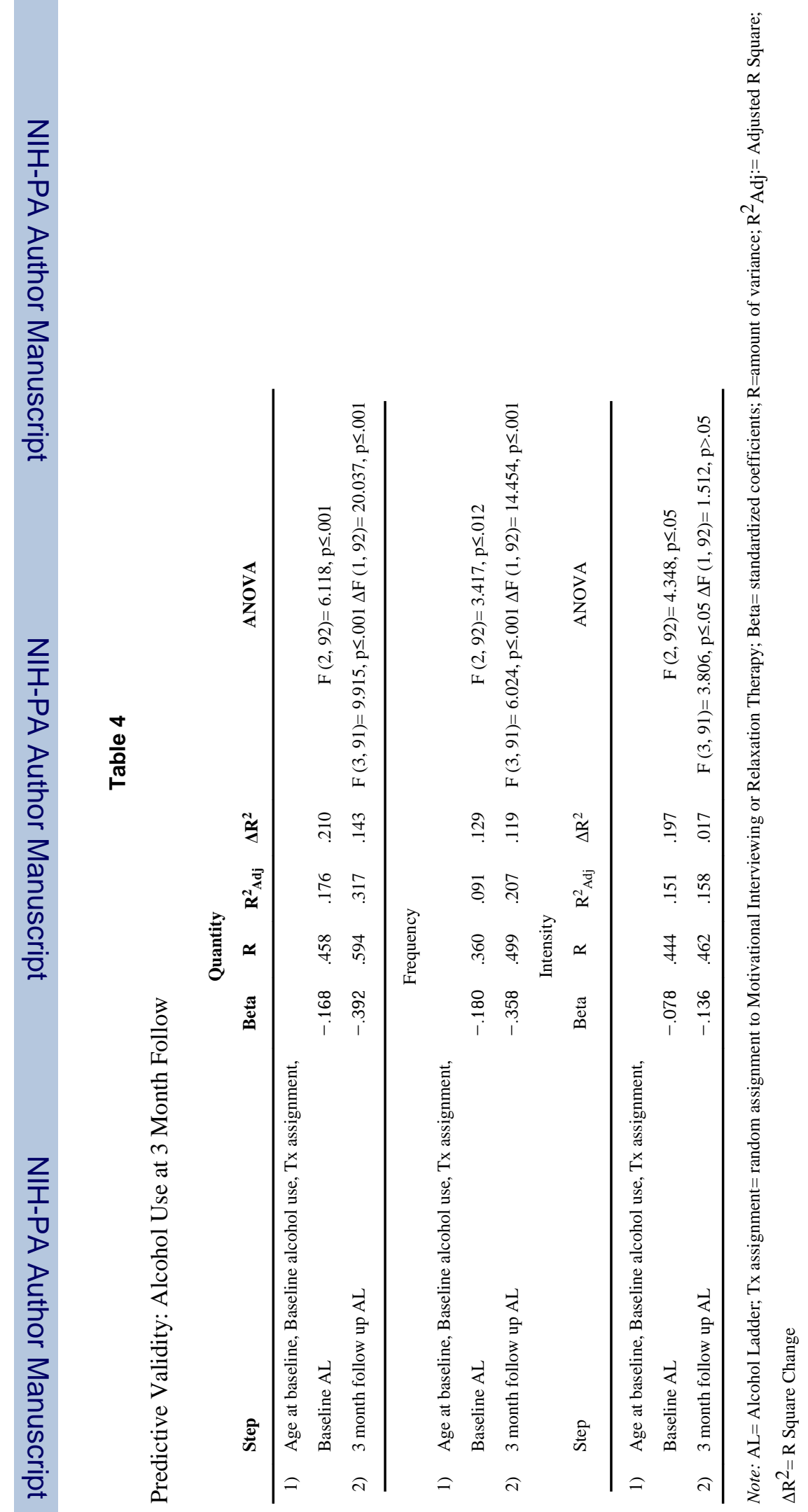

Addict Behav. Author manuscript; available in PMC 2012 June 1. 

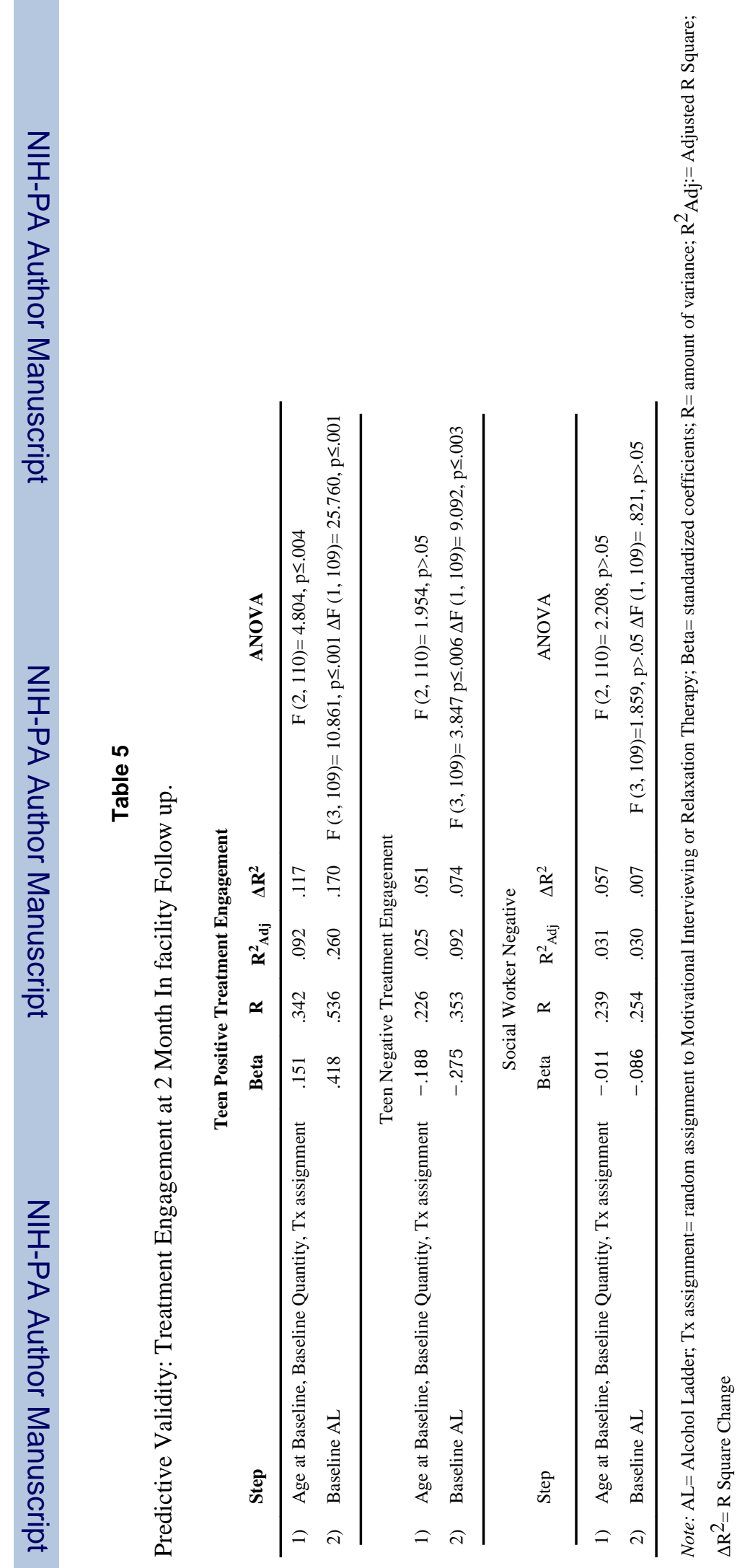

Addict Behav. Author manuscript; available in PMC 2012 June 1. 